\title{
Relationship between Policy and Practices of Decision Making in Public Schools
}

\author{
Rabindra Shiwakoti \\ rabindra2028@gmail.com \\ Lecturer \\ Central Department of Education \\ Tribhuvan University
}

\begin{abstract}
This study is critically analyzed the relationship between policy and practices of decision making in public schools of Nepal. I tried to explore the relationship between policy and practices in two districts of Kathmandu valley by using qualitative data using power and decentralization theory and different decision-making models. I understood that parents, head teacher, and teachers apply decentralization cum power theory in decision making practices in schools. I also found that these authorities mainly take decisions in physical resource management, teacher recruitment, and program extension. I also came to understand that mixed-model approach is blended between head teacher, teacher and community control model.
\end{abstract}

At the practicing level, I found gap in the use of power in various aspects of decision making. I also found that these gaps were observed because of practicing of head teacher control model. The study implies that decision making process at the school level needs a new model that must be more contextual and participatory for the effective school management.

Key Words: Decision making, policies, practices, school management, participatory, decision making model.

\section{Introduction}

Decision making process includes the steps like identifying problem, selecting an alternative, and evaluating the decision's effectiveness. In fact, it is the process of choosing the best solution among available alternatives. In this regard, it is a process that consists of the activities such as, identifying a problem, identifying decision criteria, allocating weights to the criteria, developing alternatives, analyzing alternatives, selecting best suitable alternative and evaluating decision effectiveness (Shami \& Waqar, 2007).Every People take decision in their every steps of life. But, the decision making process is different from institution to institution and person to person. Research findings show that there are various types of decision making bodies in an institution. In this regard, school management committee is one of the primary bodies that make decisions 
on the overall aspects of the schools. The roles and responsibilities of decision-making bodies are defined in current education acts and regulations. The decision-making processes may contribute significantly to managing admission process and supervise instructional practices in the classrooms (Rashid, 2009). This process also arranges additional activities for proper implementation of curriculum and its evaluation.

Making decisions can be complex because of the large number of factors influence the decision making process. There are two influencing factors in decision making process; internal factors (SMC members as an individual such as their values, goals, and priorities) and external factors (cultural and community values, religion, media influence, peers, friends, and family). Thedecision-making practices in Gurukul education system was established and controlled by people's participation (Sharma, 2005). The education was offered in the Ashrams by Gurus and managed by the public. Decision making authority was also taken by the senior Gurus of the Ashrams (Parajuli, 2002).

In Rana regime, the system of education was under the monitoring of rulers. Common people had limited access on it. However, a fundamental departure was made during this period by accepting education as a state function (Parajuli, 2002) i.e. centralized management in education. The modern schooling system was initiated in Nepal with the establishment of Durbar school in 1853 A.D. Department of Education was established in 1858 for the supervision of Durbar school in Nepal. School Goshwara was set up in 1895 and made responsible for all administrative and financial management. In this context, the government appointed Mr. Caning as Principal and Mr. Ross school supervisor (Sharma, 2005). The decision-making practices were not only limited to a higher authority but also the need of public. It was realized with the political change in 1951. However, there was a wave of establishment of schools in various parts of nation but people's enthusiasm for schooling was very much disorganized and did not give more attention for quality schooling (Stiller \& Yadav, 1979, cited in Parajuli, 2002).

Later in 1954, Ministry of Education was established for the management of educational policy and administration. The formation of National Education Planning Commission in 1956 was another example of central level decision making body in the education arena of Nepal. Though it was the effort to strengthen the central system of education, it preferred the decentralized decision making of school governance (Parajuli, 2002). During 1951 to 1971, people's enthusiasm grew as a result of rapid expansion of schools; however, the government failed to channelize properly. In this period, various donor agencies supported to deal with the educational desires of the people which focused on the public decision-making practices. The proper participatory system supported on education plan (Parajuli, 2002). But there seemed to be the lack of vision and some disorders in education management and administration.

Looking at the roles in decision making practices, the state perceived two different and contradicting roles. The first was based on egalitarian principles of equality of harmony whereas the next one was contributing towards maintaining the hierarchies and differentiations by legitimizing the traditional state authorities (Parajuli, 2002). The government used to bear only partial responsibility in decision making practices in this period. School Assistance Committee 
(SAC) was formed in order to strengthen decision making practices of local community (Timalsina, 2009).Later, the plan withdrew the operation and controlled the management of the school from the local people. Then the community felt that their liability and responsibility of school management was transferred to the government (Paudel, 2003).

From the point of decentralization, the NESP made some changes like the establishment of District Education Office and District Education Committee in all 75 districts and the abolition of the school management committee of the schools (Ministry of Education, 1971). This is an initiation of the government to strengthen the local and regional level policies. Interference of politically appointed body of DEC and other factors, the DEO could not mobilize and strengthen schools and school management committees successfully. The decade of the 1980 was evaluated as very essential period for the development of new educational administration and the gradual reversal of NESP policies and programs (Bhatta, 2005). The decade was also the piloting stage for Seti Education Project for the Rural Development project and Primary Education Project (PEP). The core intention of Seti Project was to make school as a community institution by enhancing community participation. This shows an improvement on decision making practices at grassroots level. The PEP was there to achieve the cost-effective quality improvement in primary education to enhance both quality and access in primary education. Both of the projects emphasized decentralization of decision making in school management. The establishment of resource centers of school clustering, development of teaching learning materials at local level, involvement of local community and in-service on the spot training programs for school teachers and SMC members (Lamichhane et al., 1997, as cited in Bhatta, 2005) were the new attempts in the field of education.

SMC is the legal body formally constituted to manage and operate the school with the decision of the community. The existing seventh amendment of education act has defined the role and responsibility of community to operate and manage schools with the organization of SMC. Most of the school planning and activities have been done in accordance with the decisions made by the SMC. Grauwe (2001) points out that the power of SMC emphasizes on head teacher recruitment and teacher recruitment, budgetary decision and extracurricular as well as teacher's recruitment. The SMC can also become an instrument in building a political power. Even the teacher's professional organizations have been raising several questions relating to SMC decision making process.In this context, the core question is how the decision-making practices have been running in public schools and what is the relationship between policy and practices of decision making? This study aims looking in-depth relationship between policy and practices of decision making in public schools.

\section{Statement of the problem}

The well management of school is one of the key aspects for the quality improvement in the schools. Regarding the decision-making practices in schools, many criticisms are also placed against the management committee though the government has made its own regulations. The World Bank (2007) stresses that a sector strategy is likely to be effective where there is strong community and parental involvement in school. Now the question arises whether parental involvement is sufficient for effective management or not. The government of Nepal amended 
the Education Act (1971) and Education Regulation (2002) which paved the way for reforms in school education constituting an explicit recognition that SMC is the best approach. This approach has brought accountability of schools that was seriously taken after nationalization of community schools in 1971.

The SMC which was selected by parents' assembly and enhance power to SMC according to seventh amendment (2001) of Education Act (1971) which has significantly made the SMC autonomous in making decisions in school affairs. Govinda (2000) also stresses on school autonomy in decision making. The existing SMC legal body is formally constituted by real guardian assembly and DEO only documents the information. It is only the authoritative decision making body of public school. But still the existing situation of the schools suggests that this does not seem to be the best solution. Therefore, I choose this research problem and to explore the relationship between policy and practices of decision making in schools and also identify the gaps between the policies and practices.

\section{Objectives of the Study}

The main purpose of this study is to explore the relationship between policy and practices of decision making in public schools of Nepal. More specifically the proposed research study has carried the following objectives:

1. To explore the relationship between policy and practices of/in decision making

2. To identify the gaps between policies and practices of/in decision making in/of public schools of Nepal.

\section{Methodology}

This research is based on the premises of qualitative research design under interpretative paradigm. This study followed critical interpretive design to analyze and interpret the field data. The data was mostly collected through the qualitative research tools. Analysis and interpretation are made on the basis of the theories and the understanding is obtained through socio-cultural and educational contexts. The population of the study includes the members of five schools from Kathmandu and Lalitpur district. The schools are selected from the urban and rural settings using purposive sampling method based on convenience and access to the school. My purpose was to examine the relationship between policy and practices of decision-making processes in the schools. The details of informants are as follow: 
Relationship between Policy and Practices of Decision Making in Public Schools / 73

Table 1. List of Informants

\begin{tabular}{|l|c|c|l|c|}
\hline \multirow{2}{*}{ Districts } & \multicolumn{2}{|l|}{ Schools } & \multirow{2}{*}{ Informants } & $\begin{array}{l}\text { Number of } \\
\text { informants }\end{array}$ \\
\cline { 2 - 3 } & Urban & Rural & & 3 \\
Kathmandu & 2 & 1 & Head Teacher & 3 \\
& & & SMC Chairman & 1 \\
& & & School Supervisor & 2 \\
& & & Teacher Representative & 2 \\
\hline Lalitpur & 1 & 1 & Resource Person & 2 \\
& & & Sead Teacher & 2 \\
& & & School Chairman & 1 \\
& & & Resource Person & 2 \\
\hline
\end{tabular}

In this study, I used document analysis, questionnaires, interview protocols, and Focus Group Discussion (FGD) guideline to explore the relationship between policy and practices of decision making in public schools of Nepal. A comprehensive review of documents concerning with both policy and program including related research works were completed to identify policy and program provisions in relation to the relationship between policy and practices of decision making in public schools of Kathmandu and Lalitpur district. Furthermore, minutes of SMC were analyzed to make the research more reliable. Similarly, the questionnaires were administered with the help of the SMC members including teacher representative and school supervisor to collect information related to policies, practices and relationship. In this regard, different interview protocols were used for SMC chairperson and head teachers to collect information related to relationship between policies and practices of decision making. Focus group discussion guidelines were prepared to conduct discussion with the SMC members and resource persons to get required information about the relationship between policy and practices of decision making in SMC meeting of public schools. SMC members who were regular in meeting are selected for the discussion.

For the purpose of data collection, Ivisited the sample schools as uninvited guest. Initially, the researcher tried to earn trust and establish a rapport with the school staff, including the head teachers, teacher representative, SMC members, school supervisor as well as RPs being honest to the work and behaving for professional integrity. With the help of the head teachers of the selected schools, the researcher reached to the members of the school management committees. The researcher conducted a discussion with the SMC members and resource person. After informants knew about the purpose of study, time was arranged to meet them at their places of convenience, mostly it was the schools and their workplaces. Teachers and school supervisors were asked questions to explore their opinion towards decision making procedure and practice.

Furthermore, the data were analyzed and interpreted thematically linking them with the theories and the established policies as prescribed in the documents. The researcher interpreted obtained data using the power theory and the decentralization theory. In some cases, new information was obtained with the data and then the researcher interpreted them through the perspective of the 
grounded theory. The results were achieved directly from the analysis of the raw data, not from apriori models. The primary mode of analysis is the development of themes from the raw data. The general thematic categories were deduced from the research objectives. The specific thematic categories were derived from multiple readings of the raw data. The findings of the study depend on the information collected on the relationship between policy and practice of decision making in public schools in Kathmandu and Lalitpur district. Every activity was undertaken in natural setting and their relation was analyzed.

\section{Results and Discussion}

There are various ways of recruiting the teachers following the existing policies guided by government of Nepal. To select the permanent teachers, Teacher Service Commission (TSC) holds written examination in all levels. Beside this, there is also reservation quotas based on gender, marginalized groups, dalit, etc. which is also included in the total vacant posts. It is found that power theory is implied for the selection of permanent teachers and decentralization theory is implied in the selection of temporary or contract teacher. Grounded practice is very significant and it has very important roles and responsibility to school management committee in school affairs. SMC decision is mandatory for sending the teachers for training, recruiting new teacher, teacher's transfer, and distribution of scholarship, social auditing, improving school infrastructure, monitoring and supervision, and planning and programming school activities.

Power theory is completely used and head teacher control model of decision making is also practiced in maintaining relationship. In the schools, SMC members were found less educated and least informed about their roles, responsibilities and authority in school management. It was found that power theory is in use in decision making process of SMC. In connection to the decision-making model, head teacher control model is also used while taking decision from the school management committee. The school also organizes different campaigns by the permissions of SMC as mentioned in education act and education rules and regulation for active participation in public relation and public advocator in society. The overall authority of organizing and extending program of school is based on the decision of SMC.

Some schools implied the head teacher control model, and some others implied the teacher control model and majority of the school follow the community control model for the extension of program. This process can be summarized that decentralization cum power theory is used in the program extension. In the practice of program extension in public school head teacher and SMC chairperson take the initiation where they are in power. On the other hand, community member, teacher staffs and local elites take the initiation to extend the program in their school according to the needs of schools. Here, the researcher found that power theory is used and mixed- model is used in relation to the extension of different academic programs in the school. According to the education act, one of the major tasks of SMC is to formulate school plan such as school improvement plan, annual work plan and annual academic plan. While formulating the SIP, there should be close connection between SMC, teachers, head teacher, and PTA members.

In fact, SIP emphasizes on school-community links and participatory approach to facilitate them, involve the members of the community in decision-making process, promoting and encouraging 
schools to look at planning as a tool to provide local based solutions, developing better teachinglearning conditions in schools, gradual devotion of authorities and freedom of control over resources by school and community. Here, the researcher found that power theory is ignored and decentralization theory is practiced completely. There is also a connection of teacher control model, head teacher control model and community control model which the researcher has named as mixed-model. The researcher also found that the power is held by the head teacher instead of decentralization. It is where researcher noticed that head teacher is influenced by head teacher control model instead of community control model.

Political intervention is the main block to be free in decision making. Some non-qualified persons are also selected in the committee by political interference and are guided by the same political parties and ideology. This really hits the power and blocks the right decision in making the plan and policies of school for academic betterment. This shows that power theory is mostly implied that has created a problem in decision making system of school. In other words, the researcher found that (a) if the SMC is in favor of head teacher, there seems to have practiced head teacher control model, (b) if SMC is in favor of teachers, there is teacher control model and (c) if the $\mathrm{SMC}$ is in favor of community, there is the influence of community/politics control model. In this context, the researcher noticed that power is decentralized to assistant head teacher, incharges, department head and level-wise coordinator though it is not mentioned in education act and education rules and regulations.

The decentralization of authority is vested to subordinate on the basis of the favor with the head teacher and SMC. The SMC has the full authority to select and send teachers to training and for further education. This signifies that (a) teacher control model is implied if they are in favor of SMC, (b) head teacher control model is implied if they are in favor of head teacher and (c) community control model is implied if SMC is guided by specific political ideologies. There is a provision of making a special student admission campaigns (Bharna Abhiyan). The main purpose of this issue is to let the children be admitted in the school. This is also the concept of the implementation of free and compulsory education. It contributes more to achieve the national goal of education. This result indicates the decentralization theory rather than the power theory. However, some schools have their unique practices in students' enrolment different from the government rules and policies. It was guided by mix- model. Some of the sample schools had taken entrance examination whereas some schools practiced the special home visit and on the spot admission. This practice can be labeled as the use of decentralization theory and mixedmodel is followed in relation to the student enrolment in public schools.

The power theory is implied through the head teacher of resource center school and also for organizing school, and head teacher control model is found to be practiced. Coordinating with other institutions really connects the relation for sharing different ideas and techniques. Preparing the same academic plans, organizing resource center level-wise competitive programs, community work, awareness programs, etc. are the joint activities done with their active participation. The power theory is implied through the head teacher of resource center school and head teacher control model is found to have been practiced. The practice of Continuous Assessment System (CAS) which is one of new program mentioned in the School Sector Reform Program (SSRP) in 
which internal evaluation is focused on the basis of students' daily performance and behavior. This system gives the room that teachers are free to evaluate students' performance and behavior.

The discussion above shows that decentralization theory is implied and mixed model is found which is the blending between teacher control model, head teacher control model and community control model. It was also found that extracurricular activities of the school are free from community and head teacher influences. For this, special coordinator/in-charge is nominated by head teacher with the recommendation of SMC, teacher staffs and PTA meeting. She/he makes overall plan and policies for the effective organization and implementation of the purposed plans. This indicates that power theory is ignored and decentralization theory is implied here to conduct the whole activities. By regulation, the main authority of infrastructure development is of the school management committee. SMC forwards the infrastructure development plan to district education office and department of education. SMC may directly put approach to the donors for the immediate solution. The head teacher and teacher insisted that the government should have taken the responsibilities of the public schools regarding teachers' salary, building construction, and educational materials.

\section{Conclusions}

The centralized power cannot be the contextual one applied for school management. Firstly, to make more contextual decision making, there is a need of distributive power in SMC. But the practice shows that head teacher uses maximum power while enforcing policy in decision making. It was also concluded that the same process cannot be applicable in all decision making processes. Secondly, head teachers use excessive power for teacher control model when it comes to taking key decisions like teacher recruitment, infrastructure development, delegation of authority, sending teachers for professional development programs out of the school. But the same head teacher practices mixed model in financial decision viewing that $\mathrm{s} /$ he needs joint responsibility of head teacher, teacher staff, community member and PTA members.

Thirdly, SMC members are supposed to play active and key role in the process of decision making in all areas of school management like physical development, teacher recruitment, teacher professional development, coordination among other institutions, etc. but they do not seem to be aware of the roles and responsibilities allocated to them and leave the chairperson or the head teacher to accomplish all these works. The engagement of the community and SMC specifically does not seem to have been practiced as envisioned by the policy documents like SSRP and transfer of school management to community. Finally, considering the theory of decision making practices in schools in Nepal, it can be concluded that power-cum-decentralization seems to be more practical way to run the schools. This can be considered as Mixed-Model which is blending of head teacher, teacher and community control model for the collaboration of major stake holders to take appropriate decision for better quality. This has helped all the stakeholders to have a sense of belongingness towards the school thus contributing in overall development of school in a more participatory manner. 
Relationship between Policy and Practices of Decision Making in Public Schools / 77

\section{Implications}

Going through the conclusions, the researcher has generated some implications as well. The first policy level related implication is that we have to conduct the discussion sessions among the stakeholders of education and then reach to the conclusion, whether the decision making policy is appropriate for implementation or not. If head teachers take interest, they can make it possible. Secondly, though it has been mentioned in the policy documents, there seems to be lack of clear procedure on the decision-making practices with specific roles and responsibilities of the SMC, head teacher, and PTA. Therefore, a clear policy and procedure should be drafted by the Ministry of Education, Science, and Technology to avoid the overlap of power among different agencies to implement the school education program. To formulate this kind of policy, the Ministry of Education, Science, and Technology can take the lead and have wider discussion among all the stakeholders like SMC members, head teachers, teachers and community members along with experts working in policy level. Focus group discussion in leading schools in different regions could be conducted by the ministry through District Education Offices.

The government has decentralized the authority to run the schools to the management by delegating the entire responsibility of operation but this autonomy does not seem to be very effective model because of lack of financial autonomy. This implies that we have to motivate the community schools to become independent in decision making. Before implementing the practices of decision making at operational level, community requires to be made capable to think and decide on various aspects related to school system. After knowing their responsibility, they can be more accountable towards the improvement of the schools. This implies that SMC members need orientation when they are elected in the committee. This process demands the use of decentralization cum power theory and mixed- model at the school level decision making process. Finally, this study implies the practice of mixed-model which is the output of the collaboration of head teacher, teacher and other stakeholders of education and the practice of community control model that can be only the practical measure.

\section{References}

Basic and Primary Education Project (BPEP II) 1999 - 2004. Project implementation plan (Main Report) Nepal: His Majesty Government Ministry of Education: Kathmandu.

Bhatta, P. (2005). Decentralization of primary education in Nepal. Kathmandu: Author

Govinda, R. (2000). School autonomy and efficiency: some critical issues and lessons. In Improving school efficiency: the Asian experience. Paris: IIEP, UNESCO.

Grauwe, A. D. (2001). School based management: the lessons learned. In IIEP News Letter October-December p 10. Paris: IIEP, UNESCO.

Kanun Kitab Byabastha Samitee. (2002). Education Regulation, 2059 BS. Kathmandu: Author.

Ministry of Education and Sport. (2005). Education Act 1971 (Eighth Amendment). Kathmandu: Author

Ministry of Education. (1971). National Education System Plan. Kathmandu: Author. 
Parajuli, M. N. (2002). The state, the school and the society: Dilemmas and crisis in education in Nepal. Unpublished PhD dissertation. The Danish University of Education, Copenhagen: Denmark.

Paudel, B. R. (2003). Stakeholders' participation in Education: A vital dimension of decentralization. An unpublished dissertation, submitted to the Danish University of Education, Copenhagen Denmark.

Rashid, M. (2009). Impact of professional development on the performance of secondary schools' heads. Rawalpindi; Unpublished Master in Education thesis, Fatima Jinnah Women University Reddy, R.S. (2006). Modern encyclopedia of secondary education. New Delhi: Rajat Publications.

Shami, P.A. and Waqar, A. (2007). Educational Management (module). Islamabad: Academy of Educational Planning and Management.

Sharma, G.N. (2005.). Development of Educational Administration in Nepal. Kathmandu: Makalu Books and Stationeries.

SSRP, (2009). School sector reform plan of action. Kathmandu: Author

Timalsina, B. (2009). Capacity building of SMC for leadership role in school management. An unpublished M.Phil. Dissertation submitted to School of Education, Kathmandu University.

World Bank. (2007). What is School Based Management? Washington D. C: A 